\title{
A Study on Alluvial Soil Stabilization using Bitumen Emulsion
}

\author{
${ }^{1}$ Khalid Akbar Shah, ${ }^{2}$ Dr. Esar Ahmad \\ ${ }^{1}$ Post Graduate Scholar, Mewar University, Chittorgarh \\ ${ }^{2}$ Assistant Professor\& HOD, Civil Engg Dept, Mewar University, Chittorgarh
}

\begin{abstract}
The main objective of this study is to improve the properties of the Alluvial soil by adding bitumen emulsion. An attempt has been made to use emulsion for improving the strength of Alluvial soil expressed in terms of CBR values which may prove to be economical. In this study, the whole laboratory work revolves around the basic properties of soil and its strength in terms of CBR. A little cement added to provide better soil strength. It is observed that excellent soil strength results by using cationic bitumen emulsion (CMS) with little quantity of cement used as filler. The appropriate mixing conditions for Alluvial soil with CMS Bitumen emulsion have been first attempted. This is followed by deciding four particular material conditions to show the variation in dry density and CBR value to achieve the best possible strength properties of Alluvial soil. The most important part of a road pavement is subgrade soil and its strength. If strength of soil is poor, then stabilization is normally needed. Subgrade is sometimes stabilized or replaced with stronger soil material so as to improve the strength. Such stabilization is also suitable when the available subgrade is made up of weak soil. Increase in sub grade strength may lead to economy in the structural thicknesses of a pavement. Cement, fly ash, lime, fibers etc. are very commonly used for soil stabilization.
\end{abstract}

Keywords: Alluvial soil, CBR, Bitumen Stabilization, bitumen emulsion

\section{INTRODUCTION}

Soil is the most abundant construction materials of nature. Just about all kind of construction is based with or upon the soil. Long term performance of pavement structures is altogether affected by the strength and durability of the subgrade soils. In-situ sub-grades frequently don't provide the support required to achieve acceptable performance under the traffic loading with increasing environmental demands. Despite the fact that stabilization is a well-known option for improving soil engineering properties yet the properties determined from stabilization shift broadly because of heterogeneity in soil creation, contrasts in micro and macro structure among soils, heterogeneity of geologic stores, and because of chemical contrasts in concoction interactions between the soil and utilized stabilizer.

\subsection{Objective of work}

The main objective of my study work is to improve the properties of the Alluvial soil by adding little bit cement as filler and bitumen emulsion as stabilizing agent. An attempt has been made to use emulsion for improving the strength and geotechnical properties of Alluvial soil. Very mostly, use of use of bitumen emulsion is environmentally accepted. The experiments which to be conducted are Specific Gravity of the soil sample, Grain size Distribution of soil sample and liquid limit plastic limit test to identify the material and Standard Proctor test to obtain maximum dry density and optimum moisture content of soil sample, CBR test of soil sample mixing with emulsion and cement. So the main objective is to maximize the CBR value by checking some conditions to increase the CBR value of soil subgrade.

\section{STUDY AREA}

Srinagar is the largest city and the summer capital of the Indian union territory of Jammu and Kashmir. It lies in the Kashmir Valley on the banks of the Jhelum River, a tributary of the Indus, and Dal and Anchar lakes.

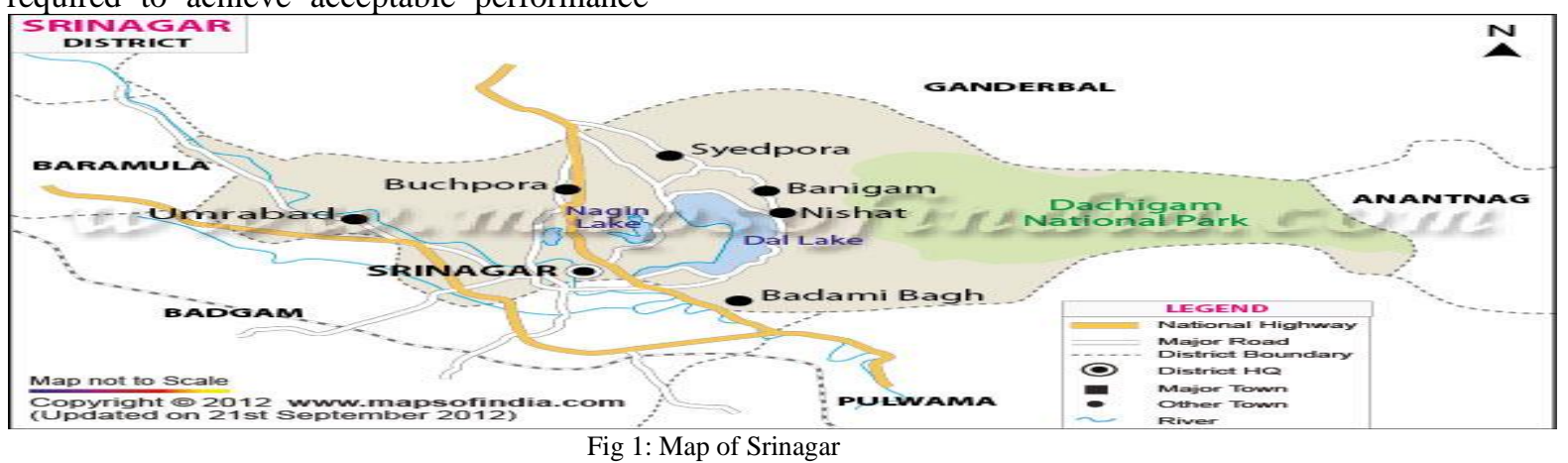

\section{MATERIAL AND METHODOLOGY}

In my work locally available in Srinagar Alluvial soil is taken as experimenting material. Medium setting emulsion (MS) is used as stabilizing agent in this particular study. Bitumen sand stabilization is an effective process as bitumen makes soil stronger and improves resistance capacity against water and frost. Actually bitumen is a very effective agent for sand stabilization but for soil stabilization it is being very costly. There is no any particularly following process or method for soil bitumen stabilization and most importantly there is no any code for bitumen soil stabilization in Indian Standard. This experiment study deals with some specific tests like Modified Compaction Test, CBR Test and the main 
objective is to optimize the strength of Alluvial soil or improve the dry density property in this project also attempt was made to maximize optimizing stability changing the mixing process with bitumen emulsion.

Selection of material and methodology those are the first criteria for any type of experimental investigation. To know the soil physical properties following tests are conducted like specific gravity test, grain size distribution test by sieve analysis and plastic limit and liquid limit test. After that the important part is to choose mixing procedure and the cases or different conditions for conducting the next tests. To determine the maximum dry density of the material modified proctor test has been conducted. But the actual goal is to increase the strength. So CBR test are conducted in different cases and conditions and make a comparative experimental study. So the methodology is how to achieve maximum bearing capacity or maximize the CBR value.

4. RESULTS

Table 1: Specific gravity test result

\begin{tabular}{|cccccc|}
\hline Sample No & M1 (gm) & M2 (gm) & M3 (gm) & M4 (gm) & Sp. Gravity \\
1. & 114.67 & 164.67 & 383.56 & 351.87 & 2.73 \\
2. & 113.76 & 163.76 & 384.41 & 352.86 & 2.71 \\
3. & 115.34 & 165.34 & 385.69 & 353.94 & 2.74 \\
\hline
\end{tabular}

Here soil material is tested three times. And the average specific gravity value comes 2.726 . But here no temperature correction is done. This test have been done in room temperature nearly $25^{*} \mathrm{C}$.

\section{Liquid limit and Plastic limit Test Results}

From these experimental results a proper idea about the type of soil has been found.

$\begin{array}{ll}\text { Liquid Limit (WL): } & 28.91 \% \\ \text { Plastic Limit (WP): } & 21.67 \% \\ \text { Plasticity Index (IP): } & 7.24 \%\end{array}$

\section{Grain Size distribution}

Various physical and engineering properties with the help of which soil can be properly identified are called index properties

Here 2000 gm of sample soil was taken and dried in oven for 12 hours. Mostly used test for grain size distribution analysis is sieve analysis. Eleven sieves were used. And the results from sieve analysis of the soil are plotted on a semi-log graph with particle diameter or the sieve size in $\mathrm{X}$ axis and percentage finer in $\mathrm{Y}$ axis.

Table 2.: Grain Size distribution result

\begin{tabular}{|c|c|c|c|c|c|}
\hline $\begin{array}{c}\text { Sieve No. } \\
\quad \#\end{array}$ & $\begin{array}{c}\text { Sieve } \\
\text { size }\end{array}$ & $\begin{array}{l}\text { Mass of soil } \\
\text { retained in each } \\
\text { sieve (gm) }\end{array}$ & $\begin{array}{c}\text { Percent } \\
\text { retained }(\%)\end{array}$ & $\begin{array}{l}\text { Cumulative } \\
\text { retained (\%) }\end{array}$ & $\begin{array}{c}\text { Percent } \\
\text { finer }(\%)\end{array}$ \\
\hline 1/2 Inch & $12.5 \mathrm{~mm}$ & 0 & ----- & 0 & 100 \\
\hline 3/8 Inch & $9.5 \mathrm{~mm}$ & 99.1 & 4.95 & 4.95 & 95.05 \\
\hline 1/4 Inch & $6.3 \mathrm{~mm}$ & 318.8 & 15.94 & 20.84 & 79.16 \\
\hline$\# 4$ & $4.75 \mathrm{~mm}$ & 397.5 & 19.88 & 40.77 & 59.33 \\
\hline \#8 & $2.36 \mathrm{~mm}$ & 510.2 & 25.51 & 66.28 & 33.72 \\
\hline$\# 16$ & $1.18 \mathrm{~mm}$ & 255.1 & 12.71 & 79.03 & 20.97 \\
\hline$\# 30$ & 600 micron & 166.2 & 8.31 & 87.34 & 12.66 \\
\hline \#50 & 300 micron & 132.1 & 6.61 & 93.95 & 6.05 \\
\hline$\# 80$ & 150 micron & 48.7 & 2.44 & 96.39 & 3.61 \\
\hline Pan & ----- & 72.3 & 3.6 & 100 & 0 \\
\hline
\end{tabular}




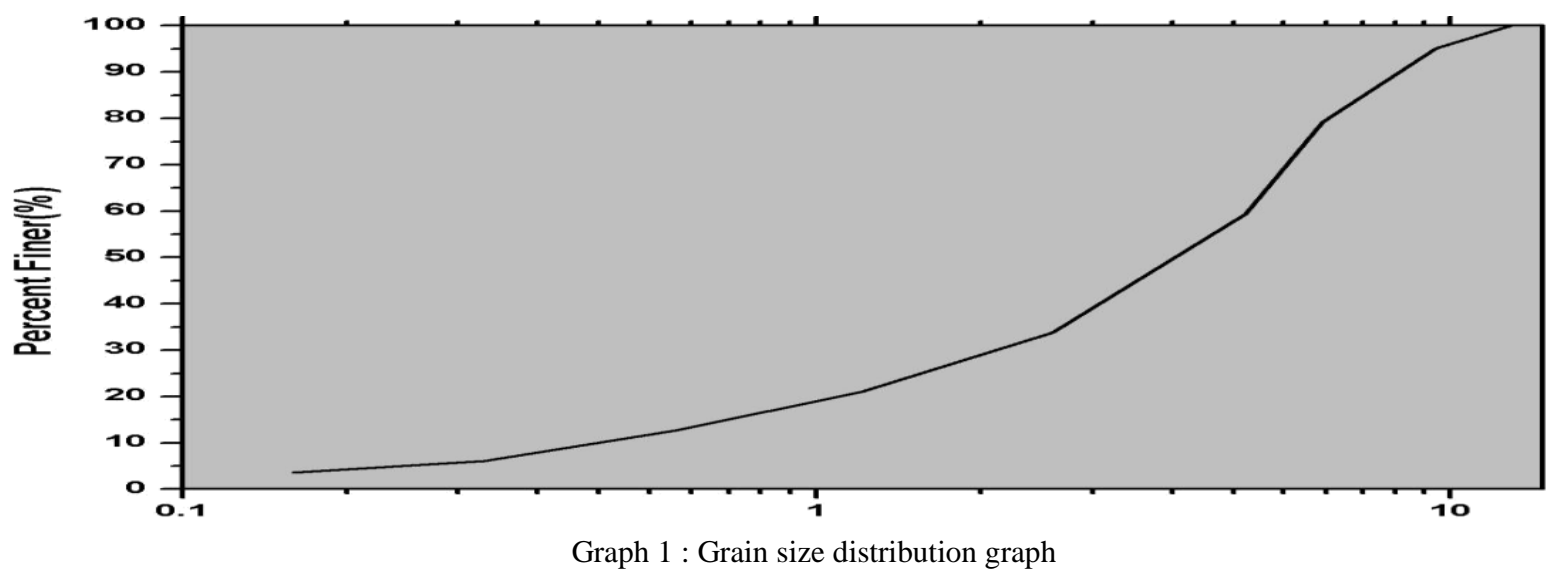

\section{Compaction Test Results}

From this test, maximum dry density of the specimen was found to be $2.026 \mathrm{gm} . / \mathrm{cc}$ and OMC of $10.52 \%$.The common matter on both works is to provide the optimum value on bitumen content percentage $3 \%$ to $4 \%$. After testing in different percentage $3 \%$, $5 \%$ and $7 \%$ it is seen that maximum dry density of this soil is not so much effectively changed. As it is used as a stabilizing agent to being applicable it should be economical. So, $3 \%$ emulsion is taken in this particular study. As I previously said very few works had done on bitumen soil stabilization. Only bitumen sand stabilization IS code is available. So, how to mix the Alluvial soil with emulsion is the main problem. Therefore four particular conditions for testing are used here to check the variation of maximum dry density of this Alluvial soil mixing with emulsion.

Condition I: $\quad$ Normal available tested soil is used for testing

Condition II : $\quad$ Normal available soil tested with $3 \%$ MS emulsion added

Condition III: $\quad$ Normal available soil tested with $3 \%$ MS emulsion and $2 \%$ cement added

Condition IV : $\quad$ Normal available soils tested mixing with $3 \%$ of emulsion and $2 \%$ of cement added and wait 5 hour before testing. In this four particular condition modified proctor test is performed and plotted with moisture content percentage in $\mathrm{X}$ axis and corresponding dry density value in $\mathrm{Y}$ axis. From carves of graphs plotted, there is a crown point where the value of dry densityis maximum. Here corresponding moisture content is optimum moisture content. In this four particular conditions tested modified proctor graph listed below. Those graphs strictly indicate that Case D gives the optimum value.
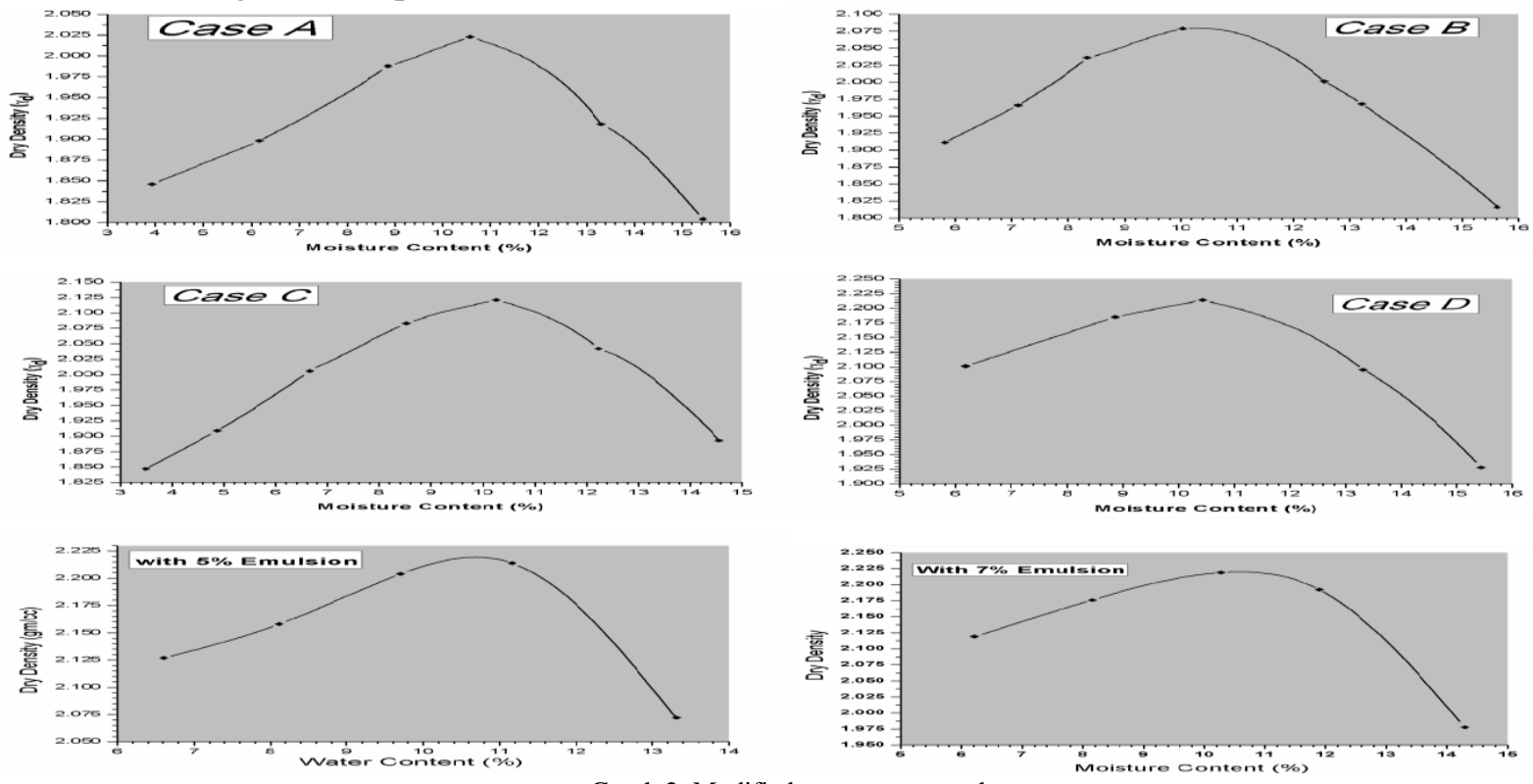

Graph 2: Modified proctor test graphs 


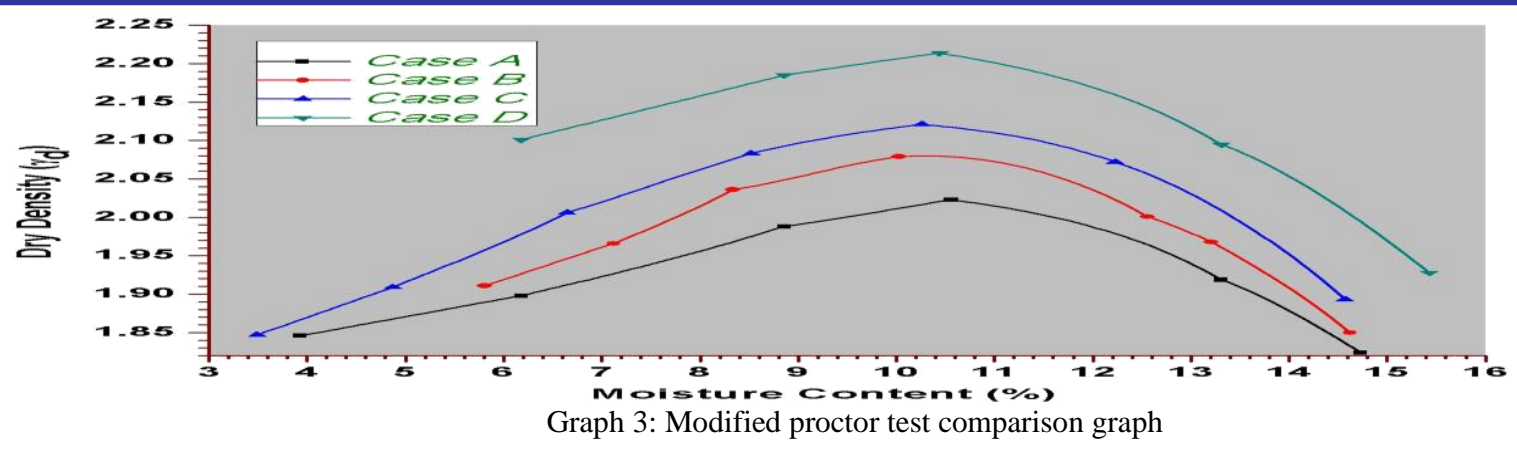

From the previous modified proctor result it is strictly showing how the dry density value for the same material is going to increase from case $\mathrm{A}$ to case $\mathrm{D}$, which is the change of maximum dry density value from $2.026 \mathrm{gm} / \mathrm{cc}$ up to $2.212 \mathrm{gm} / \mathrm{cc}$. Little bit of fluctuation in optimum moisture content value in different cases. This Yd value is a very important physical property in case of stability of subgrade soil. Bellow the variation of maximum dry density in those special cases are shown bar wise

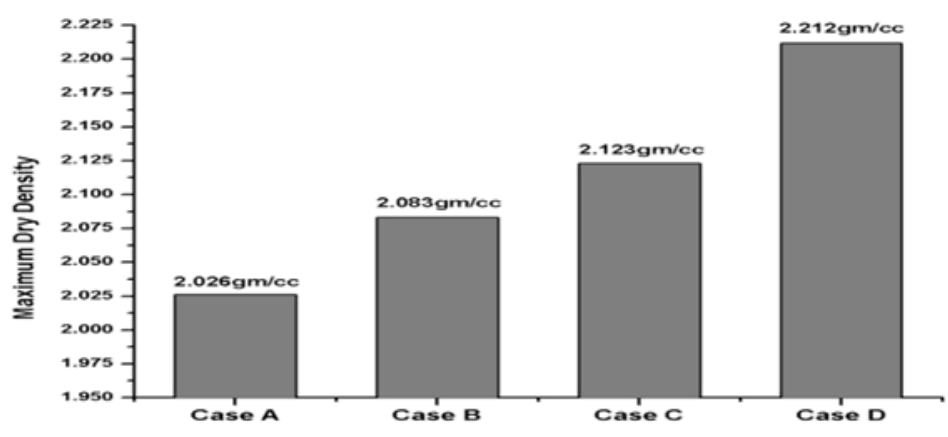

Graph 4: Variation of maximum dry density value

So again modified proctor test is done varying the bitumen content $1 \%, 3 \%, 5 \%$ and $7 \%$ following mixing procedure D. This result gives us a clear idea about used $3 \%$ bitumen content.

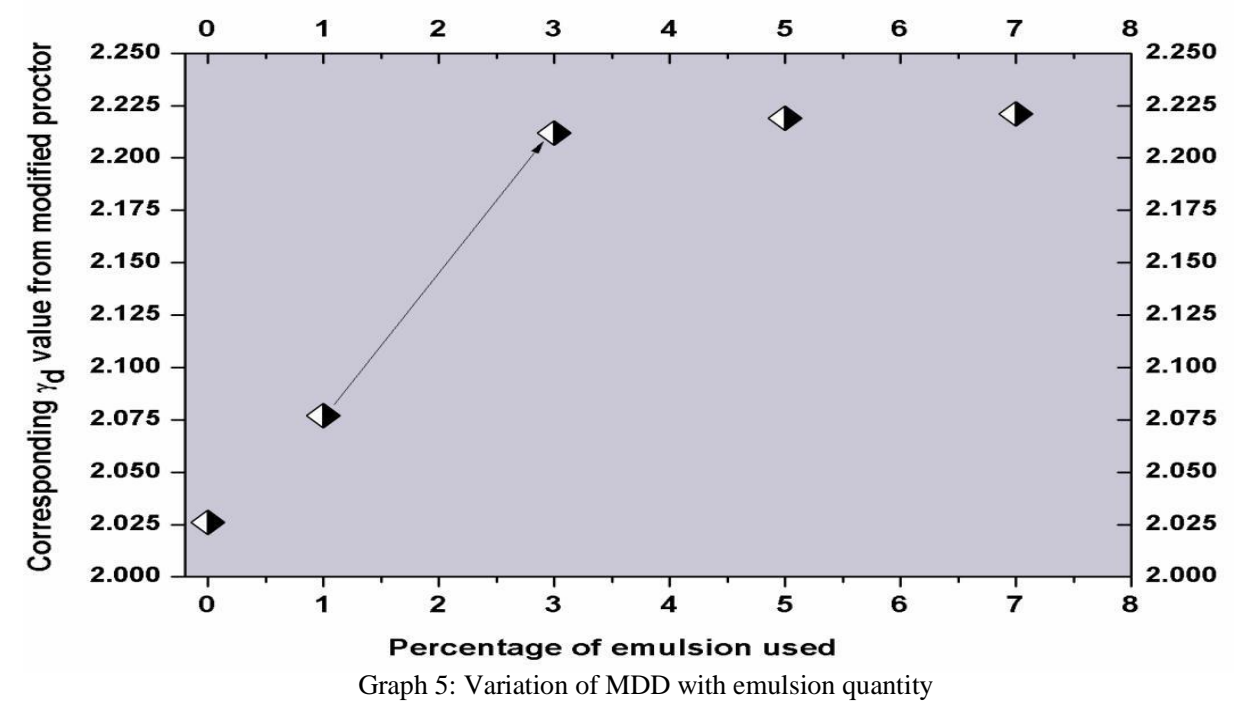

\section{Cbr Test Results}

Penetration in $\mathrm{mm}$ are plotted in $\mathrm{X}$ axis and load expressed in $\mathrm{kg}$ with corresponding points are plotted in $\mathrm{Y}$ axis and prepare graph for different specimen. The CBR values at $2.5 \mathrm{~mm}$ and $5.0 \mathrm{~mm}$ penetrations are calculated for each specimen from the corresponding graphs which is shown below. Generally the CBR value at $2.5 \mathrm{~mm}$ penetration is higher and this value is adopted.CBR is defined as the ratio of the test load to the standard load, expressed as percentage for a given penetration of the plunger. This value is expressed in percentage. Standard load of different penetration is discussed before. Here testing is done on three different testing condition on previously four cases. So total twelve number of CBR value is measured by moulding 
twelve different specimens, three different type of specimen for each case. The corresponding CBR value for each type of specimen is written on left above corner of each graph. In this comparative experimental study it is shown that how bitumen content and mixing procedure effect on CBR value of a particular soil. CBR value and the CBR graph is case wise shown below.

\section{Case A:}

Mould size: standard volume $2250 \mathrm{cc}$

Case A: Normal available tested soil is used for testing in this case Used proctor test result of Case A. Maximum Dry Density value: $2.026 \mathrm{gm} . / \mathrm{cc}$

Optimum Moisture Content: $10.52 \%$

CBR test is done in three conditions. First one is in un-soaked condition, secondly in two days of soaking condition and lastly in four days of soaking condition. CBR value at $2.5 \mathrm{~mm}$ penetration and $5 \mathrm{~mm}$ penetration is calculated.

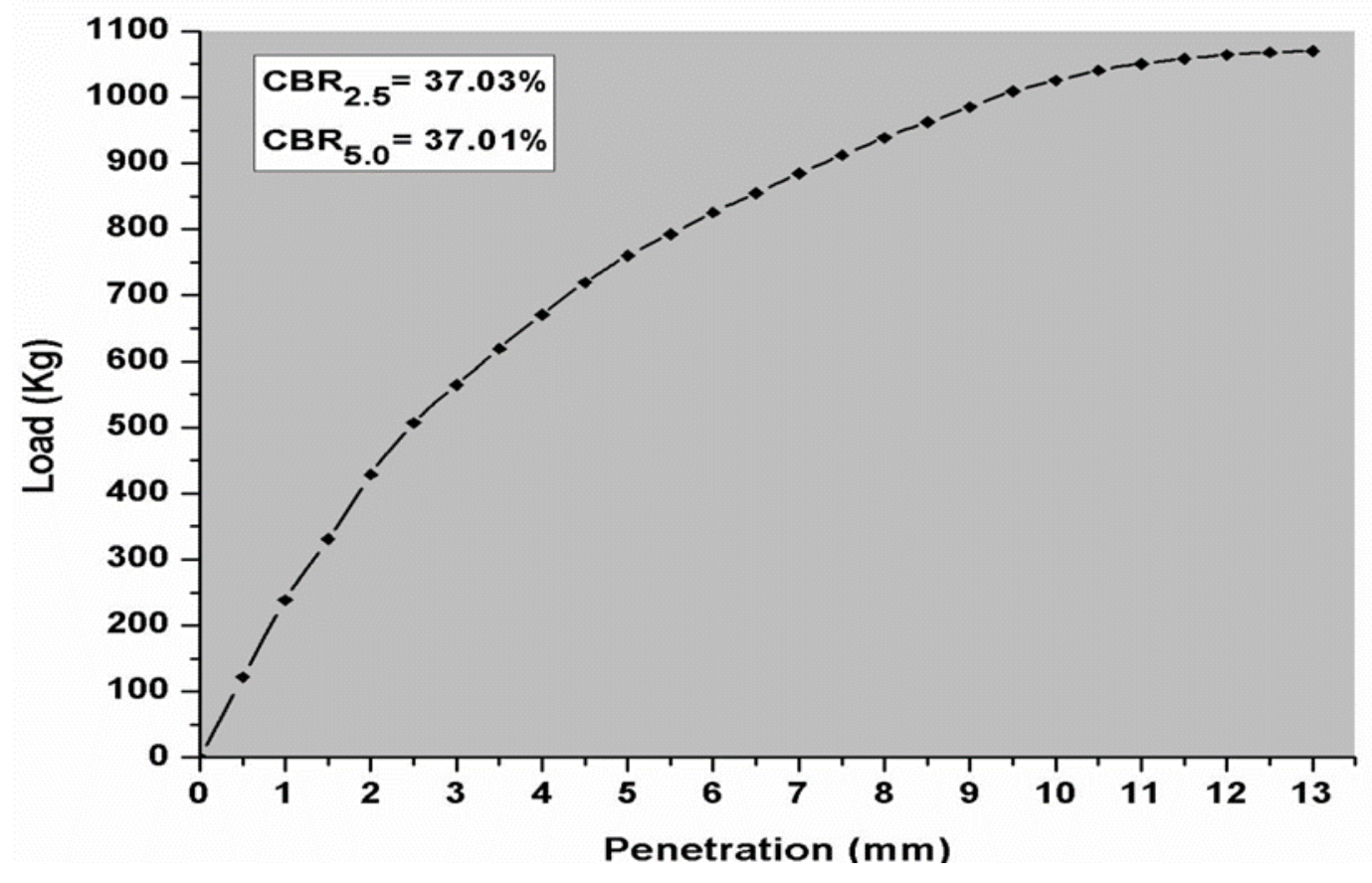

Graph 6 : CBR Test Result, Case A (Un-soaked)

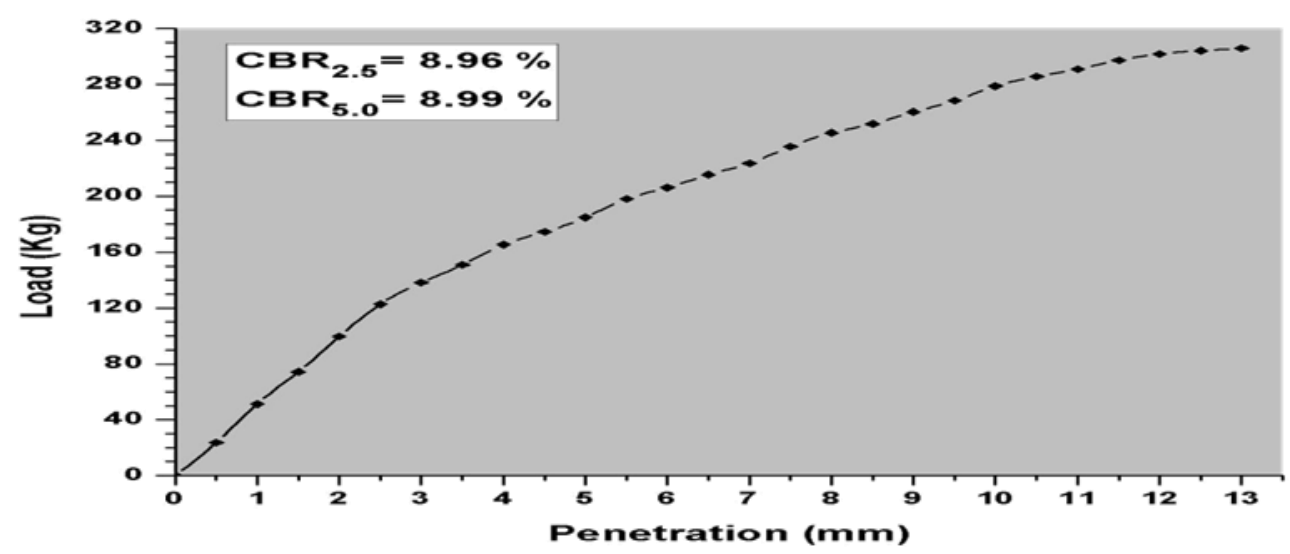

Graph 7 : CBR Test Result, Case A (2 days of soaking) 


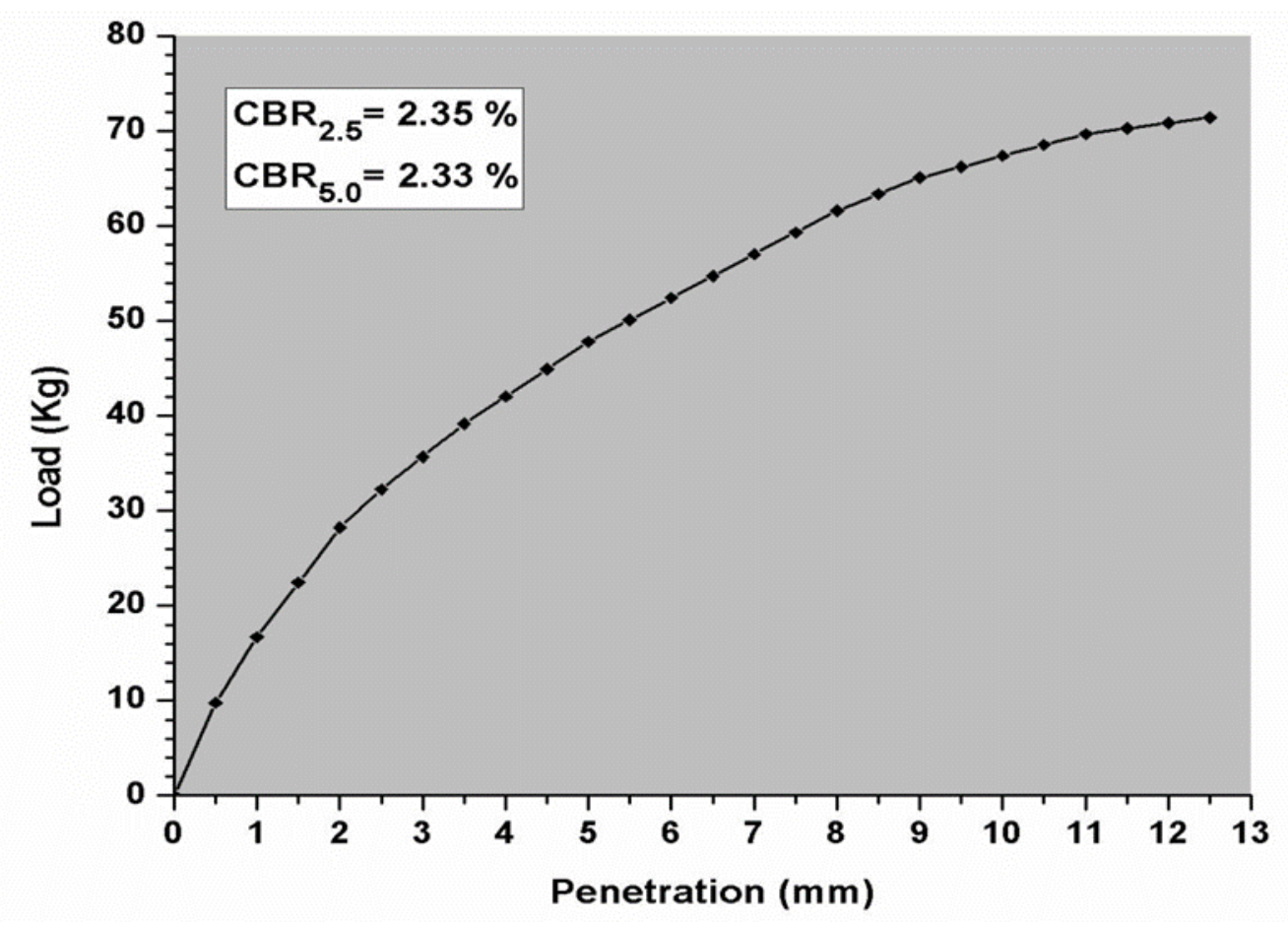

Case B:

Graph 8: CBR Test Result, Case A (4 days of soaking)

Mould size: standard volume $2250 \mathrm{cc}$

Case B: Normal available soil tested with 3\% MS emulsion added Used proctor test result of Case B. Maximum Dry Density value: $2.083 \mathrm{gm} . / \mathrm{cc}$

Optimum Moisture Content: $10.45 \%$

CBR test is done in three conditions. First one is in un-soaked condition, secondly in two days of soaking condition and lastly in four days of soaking condition. CBR value at $2.5 \mathrm{~mm}$ penetration and $5 \mathrm{~mm}$ penetration is calculated.

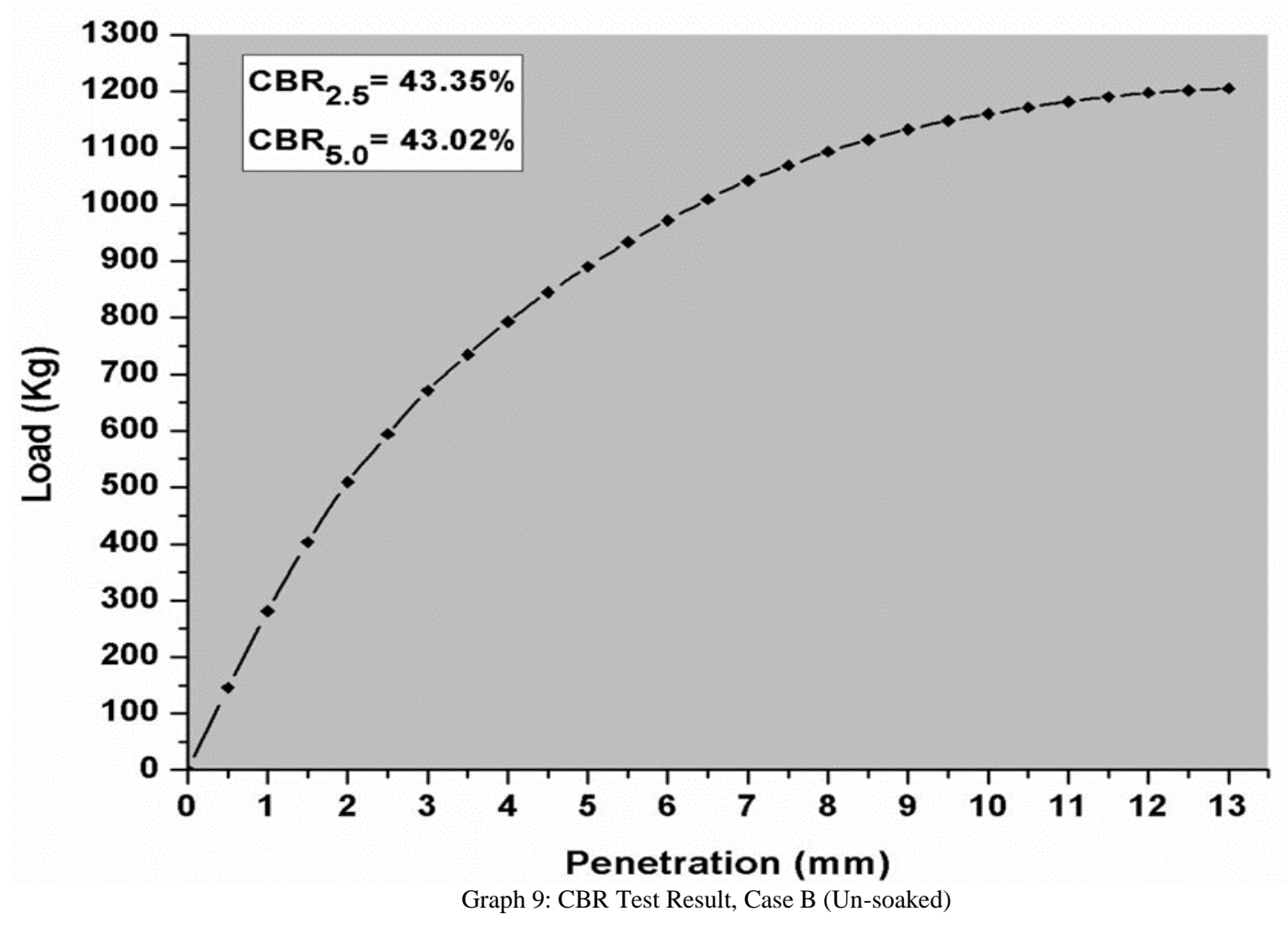




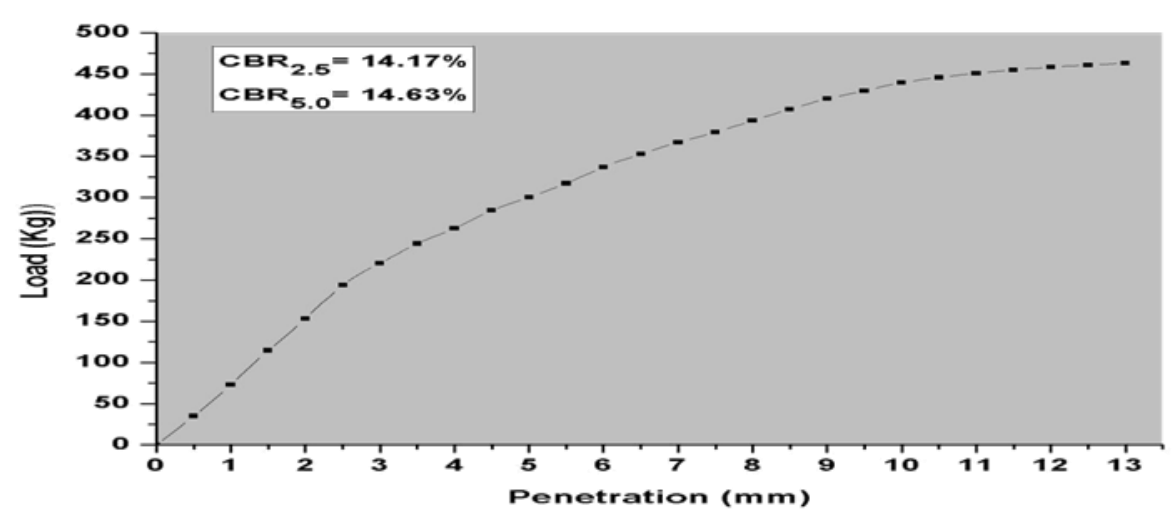

Graph 10: CBR Test Result, Case B (2 days of soaking)

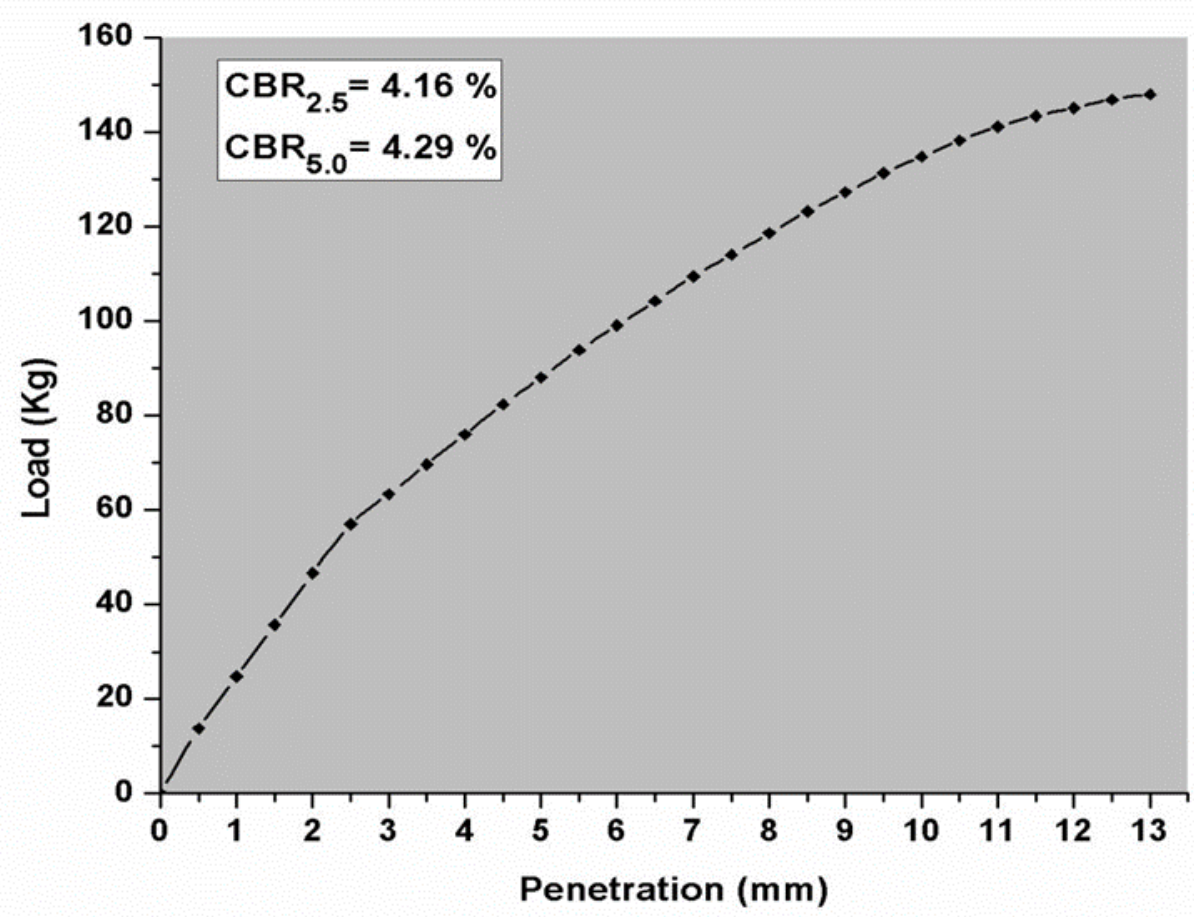

Graph 11: CBR Test Result, Case B (4 days of soaking)

\section{Case C:}

Mould size: standard volume $2250 \mathrm{cc}$

Case C: Normal available soil tested with 3\% MS emulsion and 2\% OPC cement added

Used proctor test result of Case C.

Maximum Dry Density value: $2.123 \mathrm{gm} . / \mathrm{cc}$

Optimum Moisture Content: $10.25 \%$

CBR test is done in three conditions. First one is in unsoaked condition, secondly in two days of soaking condition and lastly in four days of soaking condition. CBR value at $2.5 \mathrm{~mm}$ penetration and $5 \mathrm{~mm}$ penetration is calculated. 

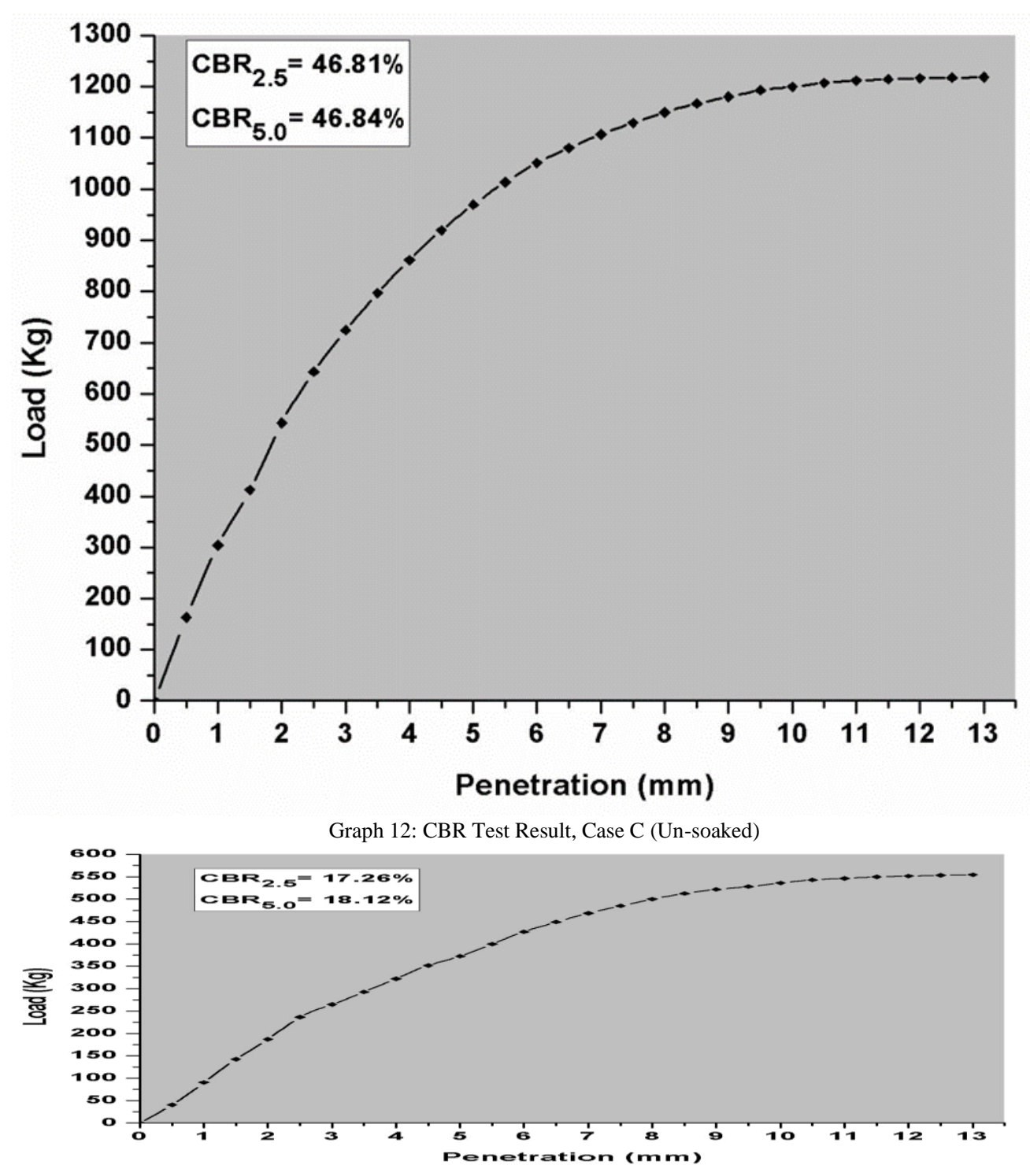

Graph 13: CBR Test Result, Case C (2 days of soaking)

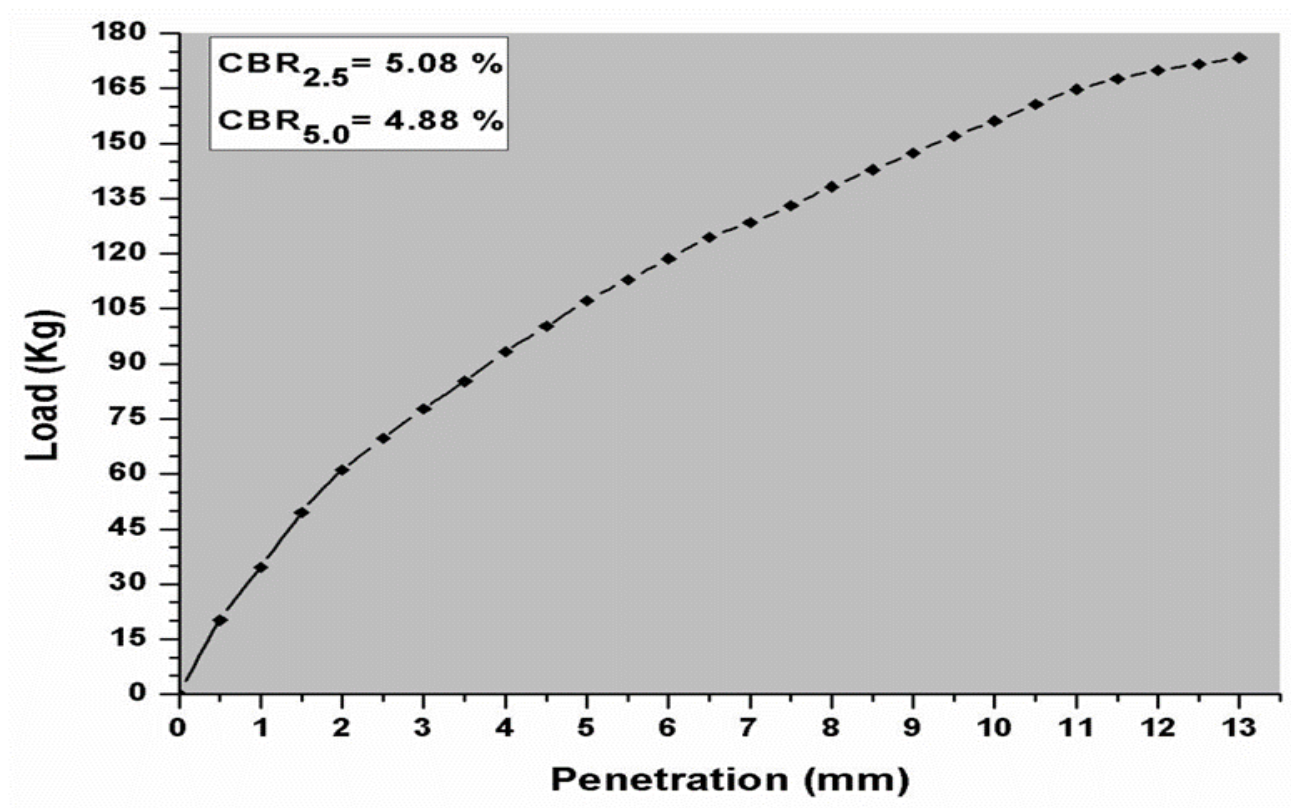

Graph 14: CBR Test Result, Case C (4 days of soaking) 


\section{Case D:}

Mould size: standard volume $2250 \mathrm{cc}$

Case D: Normal available soil tested mixing with $3 \%$ of emulsion and $2 \%$ of OPC cement added and after 5 hour testing started. Used proctor test result of Case D.

Maximum Dry Density value: $2.212 \mathrm{gm} . / \mathrm{cc}$

Optimum Moisture Content: $10.58 \%$

CBR test is done in three conditions. First one is in unsoaked condition, secondly in two days of soaking condition and lastly in four days of soaking condition. CBR value at $2.5 \mathrm{~mm}$ penetration and $5 \mathrm{~mm}$ penetration is calculated.

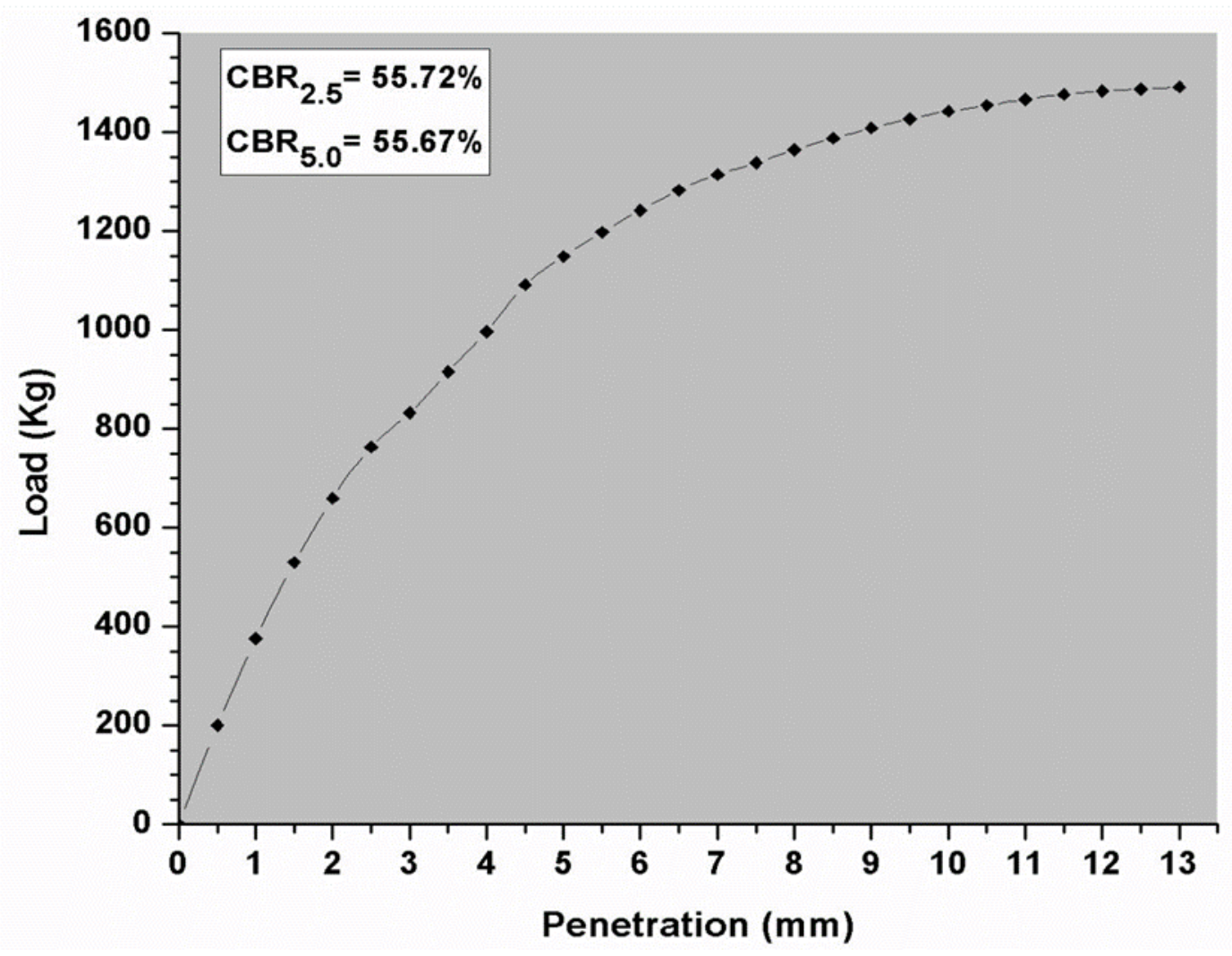

Graph 15: CBR Test Result, Case D (Un-soaked)

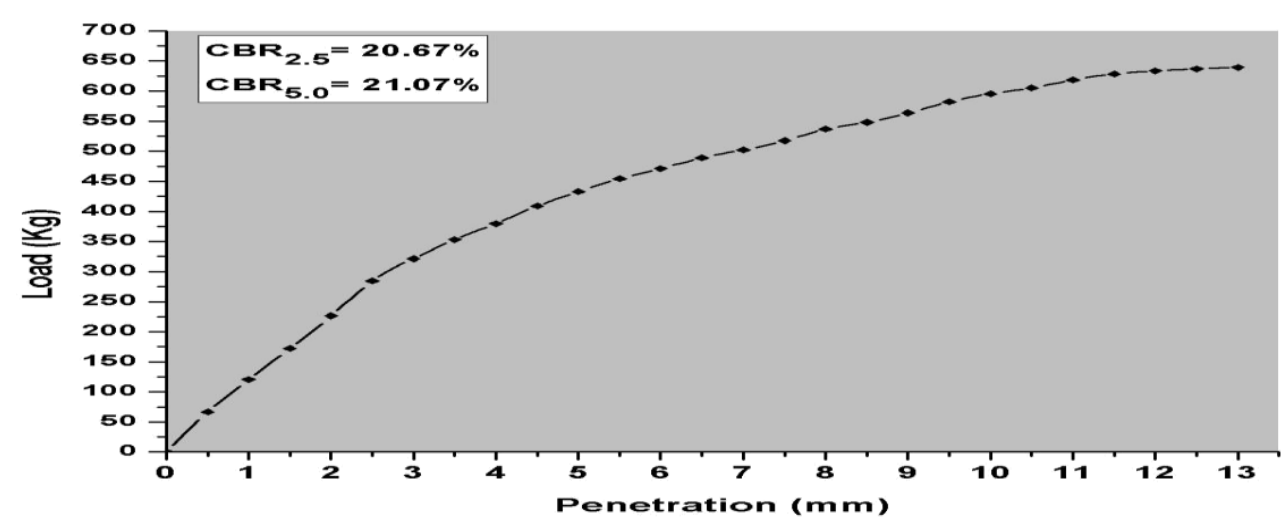

Graph 16: CBR Test Result, Case D (2 days of soaking) 


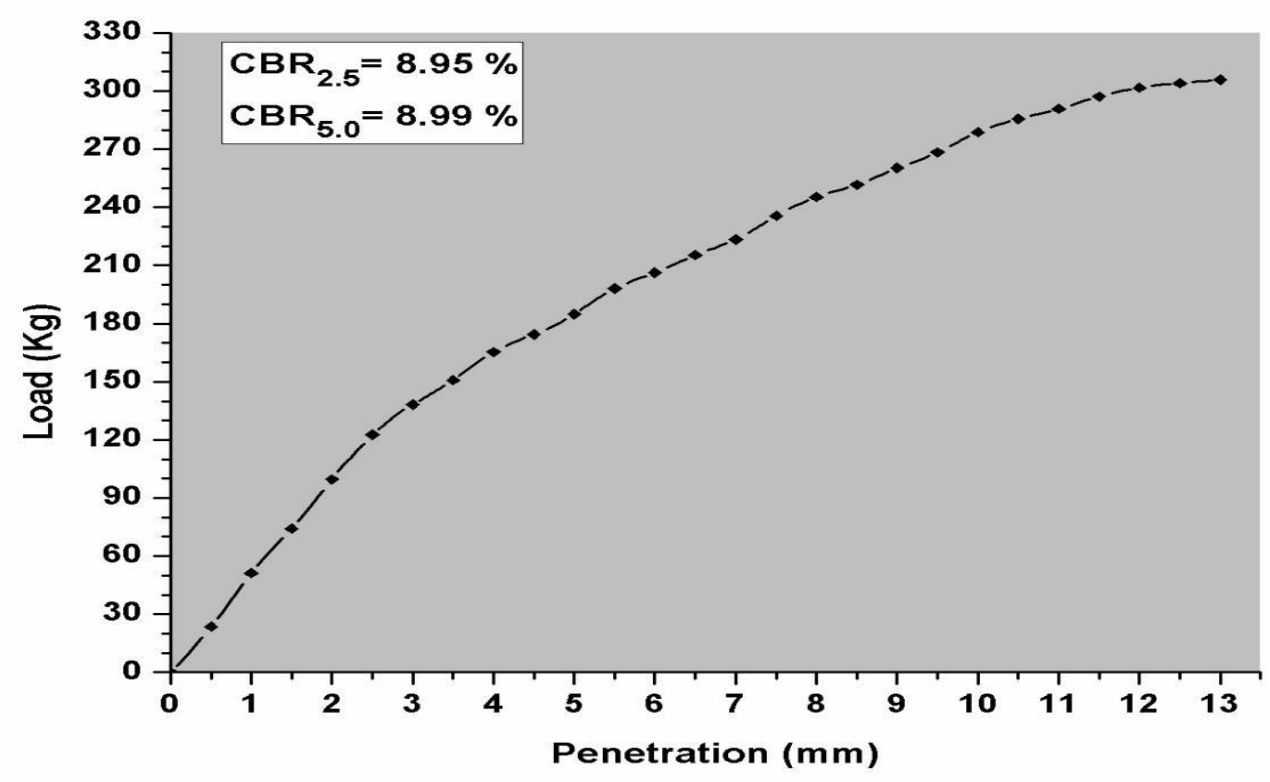

Graph 17: CBR Test Result, Case D (4 days of soaking)

\section{DISCUSSION}

Subgrade may be defined as a compacted soil layer, generally of naturally occurring local soil, assumed to be $300 \mathrm{~mm}$ in thickness, just below of the pavement crust. It provides a suitable foundation for the pavement. So it is very important to improve strength of subgrade soil, it may be by replacing good soil or by stabilization of existing soil. To check the subgrade soil stability CBR test is very commonly used test. The all CBR results are plotted in a bar to check whether the improvement of CBR is done or not and if done then what would be that condition where CBR value become maximum. Following bar gives about a clear idea on this.

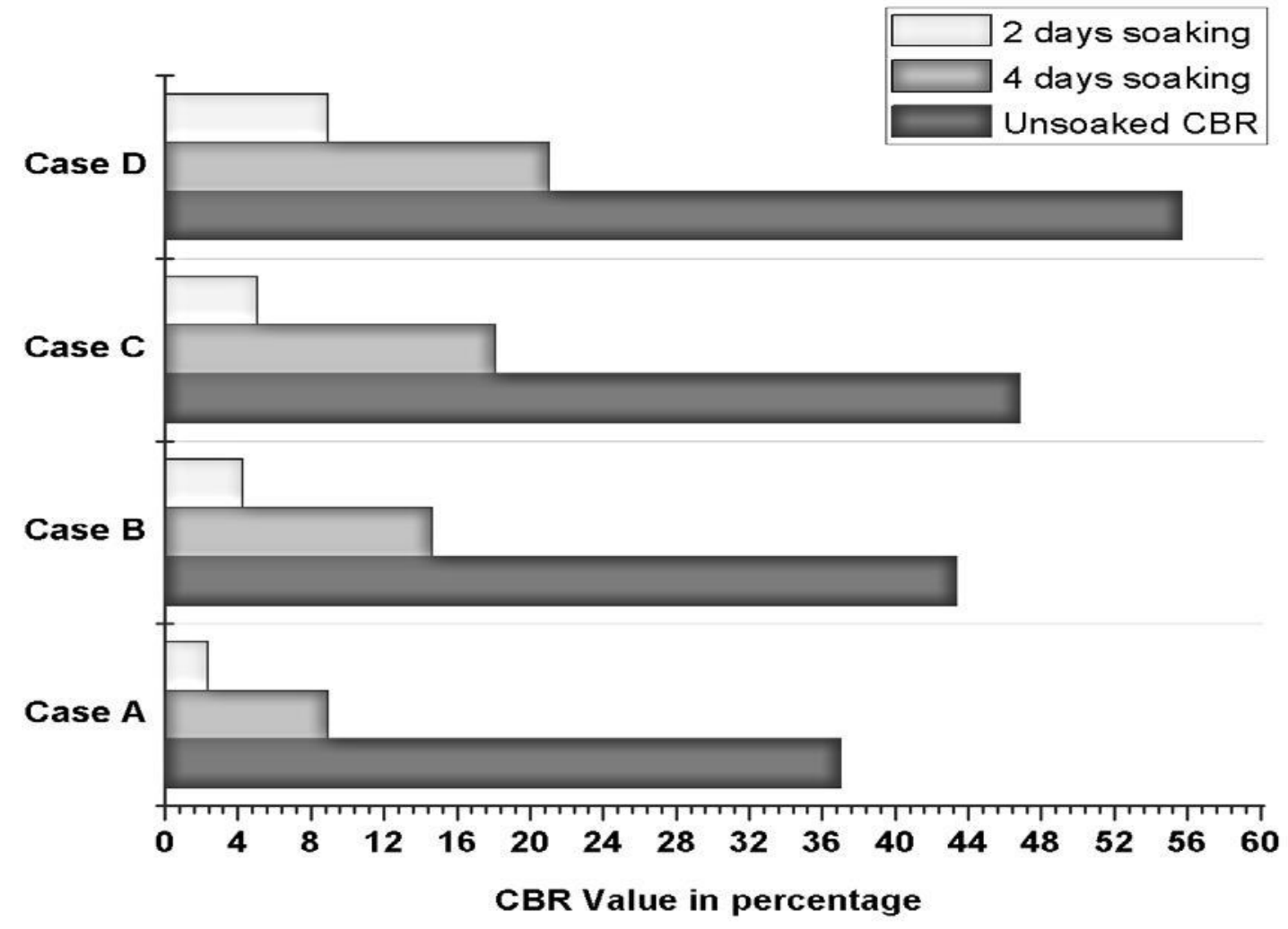

Graph 18: CBR value comparison bar chart 


\section{CONCLUSION}

From this study it is clear that there is a considerable improvement in California Bearing Ratio (CBR) of subgrade due to use of MS bitumen emulsion if proper mixing is done. It is seen that it best results are obtained if the soil emulsion mix is left for about five and half hours after mixing. In each state of condition it was found that CBR value has increased consecutively from Case A to Case D. In this particular experimental study CBR value has increased up to fifty percent of the unmodified soil CBR. Observing its economic cost and quality of stabilization improvement, it is clear that this type of stabilization may be applicable in Alluvial soil or in shoulder portion of highways.

\section{REFERENCES}

[1] Alayaki, F. M., Bajomo, O. S. (2011), Effect of Moisture Variation on the Strength Characteristics of Laterite soil. Proceedings of the Environmental Management Conference, Federal University of Agriculture, Abeokuta, Nigeria.

[2] Hodgkinson., A.T. Visser (2004), University of Pretoria and Concor Roads (Pty) Ltd, The role of fillers and cementitious binders when recycling with foamed bitumen or bitumen emulsion.

[3] Cokca.E., Erol,O., Armangil. (2004), "Effects of compaction moisture content on the shear strength of an unsaturated clay", Geotechnical and Geological Engineering

[4] Chauhan.(2010)," a laboratory study on effect of test conditions on subgrade strength".

[5] Unpublished B.Tech Thesis, N.I.T Rourkela.

[6] Consoli, N. C., Prietto, P. D. M., Carroro, J. A. H., and Heineck, K. S.(2001). "Behavior of compacted soil-fly ash-carbide lime mixture.”J. Geotech. Geoenviron. Eng., 127(9), 774-782.

[7] D. Jones., A. Rahim., S. Saadeh., and J.T. Harvey (2012), Guide lines for the Stabilization of Subgrade Soils In California, Guideline: UCPRC-GL-2010-01

[8] Gregory Paul Makusa. (2012), Department of Civil, Environmental and Natural resources engineering, Luleå University of Technology, Sweden.

[9] Jaleel,Z.T.(2011), Effect of Soaking on the CBR-Value of Subbase Soil. Eng. and Tech. journal, vol.29.

[10] Mouratidis A.(2004), Stabilization of pavements with fly-ash, Proceedings of the Conference on Use of industrial by-products in road construction, Thessaloniki, 47-57. 